\title{
The effects of fasting on plasma corticosterone kinetics in rats
}

\author{
BY C. J. H. WOODWAR D ${ }^{1}$, G. R. HERVEY ${ }^{1}$, R. E. OAKEY AND E. M. WHITAKER ${ }^{1}$ \\ ${ }^{1}$ Department of Physiology and ${ }^{2}$ Division of Steroid Endocrinology, Department of Chemical \\ Pathology, University of Leeds, Leeds LS2 $9 N Q$
}

(Received 9 March 1990 - Accepted 6 November 1990)

\begin{abstract}
Plasma corticosterone clearance in anaesthetized rats was measured from the disappearance of radioactivity after a bolus injection of $\left.\right|^{3} \mathrm{H} \mid$ corticosterone. Mean fractional clearance rates were significantly $(P<0.05)$ reduced after a $48 \mathrm{~h}$ fast, by 32 and $22 \%$ for males and females respectively. Plasma corticosterone concentrations were increased by fasting in both sexes. Corticosterone secretion rates, calculated as the product of fractional clearance and plasma corticosterone concentration, did not differ between fed and fasted groups in either sex. The mean activity (U/liver) of the rate-limiting enzyme for corticosterone degradation, hepatic 4,5-dihydrocorticosterone: $\mathrm{NADP}^{+} \Delta^{4}$-oxidoreductase, was significantly reduced by 51 and $78 \%$ after fasting in males and females respectively. This was due to changes in both the soluble and microsomal forms of the enzyme. The binding capacity of corticosterone-binding globulin in plasma was significantly reduced by fasting in females $(P<0.001)$, but was not altered in males. The results suggest that reduced hormone clearance is the dominant cause of fasting hypercorticosteronaemia in the rat.
\end{abstract}

Fasting: Corticosterone metabolism: Rat

Corticosteroids play a major role in the metabolic response to undernutrition, by causing increased release of amino acids from skeletal muscle, and their subsequent conversion to glucose in the liver (Waterlow et al. 1978; Munck et al. 1984; Tischler et al. 1988). Plasma corticosteroid concentration is generally assumed to be controlled by pituitary release of adrenocorticotrophin, which increases adrenal steroid secretion. Thus, increased levels of plasma adrenocorticotrophin and corticosteroids have been found in fasted humans (Beer et al. 1989) and in cockerels given a diet deficient in protein (Carsia et al. 1988).

The capacity of the liver to catabolize corticosterone is, however, highly dependent on the level of food consumption (Herbst et al. 1960). Since this organ is the major site of corticosteroid metabolism (Norman \& Litwack, 1987), a decreased ability to catabolize corticosterone might increase plasma steroid levels independently of changes in adrenal secretion. The aim of the present investigation was to measure the turnover rate of plasma corticosterone, in order to assess the relative contributions of reduced clearance and increased secretion to the raised corticosterone levels found during fasting. In addition, measurements have been made of the binding capacity of plasma corticosterone-binding globulin (CBG), and of the activity of hepatic 4,5-dihydrocorticosterone: NADP ${ }^{+} \Delta^{4}$ oxidoreductase (corticosterone reductase), the rate-limiting enzyme for corticosterone degradation. A preliminary report of this work has already been given (Woodward et al. 1990).

\section{MATERIALS AND METHODS}

\section{Animals}

The rats were $\mathrm{F} 1$ hybrids obtained from our breeding colonies by crossing PVG/C Lister Hooded males with WAG/C Wistar Albino females. Three experiments were carried out. 
In the first, corticosterone clearance and the capacity of plasma CBG were measured, while in the second and third the activity of hepatic corticosterone reductase was determined. The rats were aged approximately 3 months in Expt 1 and 6 months in Expts 2 and 3.

At 2 weeks before the measurement of corticosterone clearance (Expt 1), twelve male and twelve female rats were placed in individual cages and given water and a stock diet ad lib. In Expts 2 and 3, animals were caged in groups of four or five. Before the experiments, rats were either deprived of food for $48 \mathrm{~h}$ or fed ad lib.

\section{Measurement of corticosterone clearance}

The clearance rate of plasma corticosterone was measured by a method based on those of Ulrich \& Long (1956) and Herbst et al. (1960). The procedure assumes that (1), injected steroid mixes immediately and completely with a single plasma pool of steroid which does not vary in size during the measurement, and (2), the secretion rate of corticosterone is constant during the period of measurement, so that the decay of radioactivity after a bolus injection of radiolabelled steroid is exponential. The measurement of steroid clearance rates has been discussed by Tait (1963).

Rats were anaesthetized using halothane (20 g/l in oxygen), and $\left[1,2,6,7-{ }^{3} \mathbf{H}\right]$ corticosterone (Amersham International plc, Amersham, Bucks.; $93.2 \mathrm{Ci} / \mathrm{mmol} ; 2 \mu \mathrm{Ci}$ in $200 \mu \mathrm{l}$ sodium chloride solution ( $9 \mathrm{~g} / \mathrm{l}$ in water)) was injected into the femoral vein. The tail artery was immediately cannulated and blood samples of approximately $200 \mu 1$ were taken into heparinized tubes at 5, 10, and $15 \mathrm{~min}$ after injection. After $20 \mathrm{~min}$, a final blood sample was taken by cardiac puncture and the animals were killed. The radioactivity in portions $(50 \mu \mathrm{l})$ of plasma was determined by scintillation counting followed by correction for quenching. The fractional clearance rate (FCR) was calculated individually for each animal from the gradient of the regression of $\ln$ (plasma radioactivity) $v$. time. The $y$ intercepts of these plots were divided into the total amount of radioactivity injected, to obtain the volume of distribution. The secretion rate per ml plasma was calculated by multiplying FCR by the plasma corticosterone concentration in the final blood sample. Secretion rate was also calculated per whole rat, assuming plasma volume to be $3.5 \%$ of body-weight (Waynforth, 1980). Metabolic clearance rate, which is the volume of plasma cleared of steroid per unit time (Tait, 1963), was obtained from the product of FCR and estimated plasma volume. Corticosterone concentration was determined by radioimmunoassay using a commercially-available antiserum (ICN Immunobiologicals, High Wycombe, Bucks.). Samples of plasma were extracted using dichloromethane, which was then removed by evaporation. The residue was resuspended and the assay carried out as described in the manufacturer's directions.

An initial study was carried out to validate the clearance procedure, using four rats of each sex. The disappearance of radioactivity was found to follow first-order kinetics between 5 and 20 min following injection. Plasma corticosterone levels did not change significantly during this period; average concentrations were (means with SE) 0.92 (SE 0.14) and 2.45 (SE 0.17$) \mu \mathrm{mol} / 1$ for males and females respectively. Corticosterone concentrations in non-anaesthetized rats of similar weight, killed by decapitation after minimal handling, were 0.53 (SE 0.09) and 1.72 (SE 0.12) for seven males and females respectively. The final blood samples obtained by cardiac puncture were fractionated by thin-layer chromatography (Lindberg et al. 1972). Radioactivity was determined in different fractions after development with chloroform-ethanol $(90: 10, \mathrm{v} / \mathrm{v})$ and elution with methanoldichloromethane $(4: 1, \mathrm{v} / \mathrm{v})$. The percentage of total radioactivity located in the corticosterone fraction (means with SE) was 80.1 (SE 0.8) and 75.8 (SE 2.5) for males and females respectively. Since this result showed that most of the plasma radioactivity remained as corticosterone even at $20 \mathrm{~min}$ after injection, the decay curves obtained were not corrected for the presence of labelled metabolites. 
Binding capacity of plasma $C B G$

The capacity of plasma CBG was determined in the final blood samples taken by cardiac puncture, using a binding assay based on that of Martin et al. (1977). Endogenous steroids were stripped from $500 \mu 1$ plasma by mixing for $1 \mathrm{~h}$ with $25 \mathrm{mg}$ activated charcoal at room temperature. The charcoal was removed by centrifugation at $1000 \mathrm{~g}$ for $15 \mathrm{~min}$, followed by a further centrifugation of the supernatant fraction at $10000 \mathrm{~g}$ for $15 \mathrm{~min}$. Stripped plasma was diluted 140 -fold with $50 \mathrm{~mm}$-sodium dihydrogen phosphate-disodium hydrogen phosphate buffer, $\mathrm{pH} 7 \cdot 4$. Portions $(500 \mu \mathrm{l})$ were incubated overnight at $0^{\circ}$ in glass test-tubes containing $\left[1,2,6,7-{ }^{3} \mathrm{H}\right]$ corticosterone $(0 \cdot 1 \mu \mathrm{Ci})$ and either 23 or $750 \mathrm{pmol}$ non-radioactive hormone (Sigma Chemical Co., Poole, Dorset). Unbound corticosterone was then removed by mixing with $100 \mu \mathrm{l}$ dextran-charcoal solution $(50 \mathrm{~g}$ activated charcoal and $5 \mathrm{~g}$ dextran/l buffer) followed by centrifugation at $1000 \mathrm{~g}$ for $10 \mathrm{~min}$. Portions of supernatant fraction were taken for scintillation counting. Total plasma-bound corticosterone was calculated from the radioactivity in the tubes containing $23 \mathrm{pmol}$ corticosterone. A correction for non-specific binding was then made using the results obtained with the higher concentration of corticosterone (Chamness \& McGuire, 1975). Plasma protein content was determined by the Lowry method (Dawson et al. 1969) using bovine serum albumin as a standard.

\section{Hepatic corticosterone reductase activity}

Enzyme activity was measured in whole liver homogenates (Expt 2) and in soluble and microsomal fractions obtained by differential centrifugation (Expt 3). In Expt 2, liver homogenates $(12.5 \mathrm{~g} / 1)$ were prepared using fresh tissue in $10 \mathrm{~mm}$-sodium dihydrogen phosphate-disodium hydrogen phosphate buffer, $\mathrm{pH} 7 \cdot 4$. Portions were incubated with glucose-6-phosphate and a buffered solution containing corticosterone and an NADPHgenerating system, as described by Yates et al. (1958). The reaction was stopped by adding dichloromethane $(10 \mathrm{ml})$ and shaking for $1 \mathrm{~min}$. The supernatant fraction was aspirated and discarded, and the remaining solution was washed once with $1 \mathrm{ml}$ hydrochloric acid $(0 \cdot 1 \mathrm{M})$. The absorbance of the dichloromethane solution was then determined at $240 \mathrm{~nm}$. The rate of corticosterone reduction was calculated from the decrease in absorbance during incubation. Protein content was determined by the Lowry method as described by Dawson et al. (1969), using a standard of bovine serum albumin.

In Expt 3, liver homogenates $(330 \mathrm{~g} / \mathrm{l})$ were prepared in $0.25 \mathrm{M}$-sucrose solution and centrifuged at $20000 \mathrm{~g}$ for $15 \mathrm{~min}$. The pellet was resuspended and recentrifuged twice before being discarded. The supernatant fractions were combined and centrifuged at $100000 \mathrm{~g}$ for $45 \mathrm{~min}$. The resulting pellet was resuspended and recentrifuged once. The combined supernatant fractions and the pellet from the high-speed centrifugation were designated as the soluble and microsomal fractions respectively. Preliminary experiments demonstrated that no further enzyme activity was released from the precipitate by further resuspension and centrifugation at either low or high speed. The microsomal and soluble fractions were diluted appropriately and assayed for corticosterone reductase activity as described previously. In addition, the activity of the microsomal marker enzyme glucose6-phosphatase (EC 3.1.3.9) was determined (Baginski et al. 1974).

\section{Statistical methods}

Results are expressed as means with their standard errors. Means were compared using analysis of variance. Where variances were judged by variance ratio to be inhomogeneous $(P<0.05)$, the Satterthwaite correction was used (Snedecor \& Cochran, 1978). 

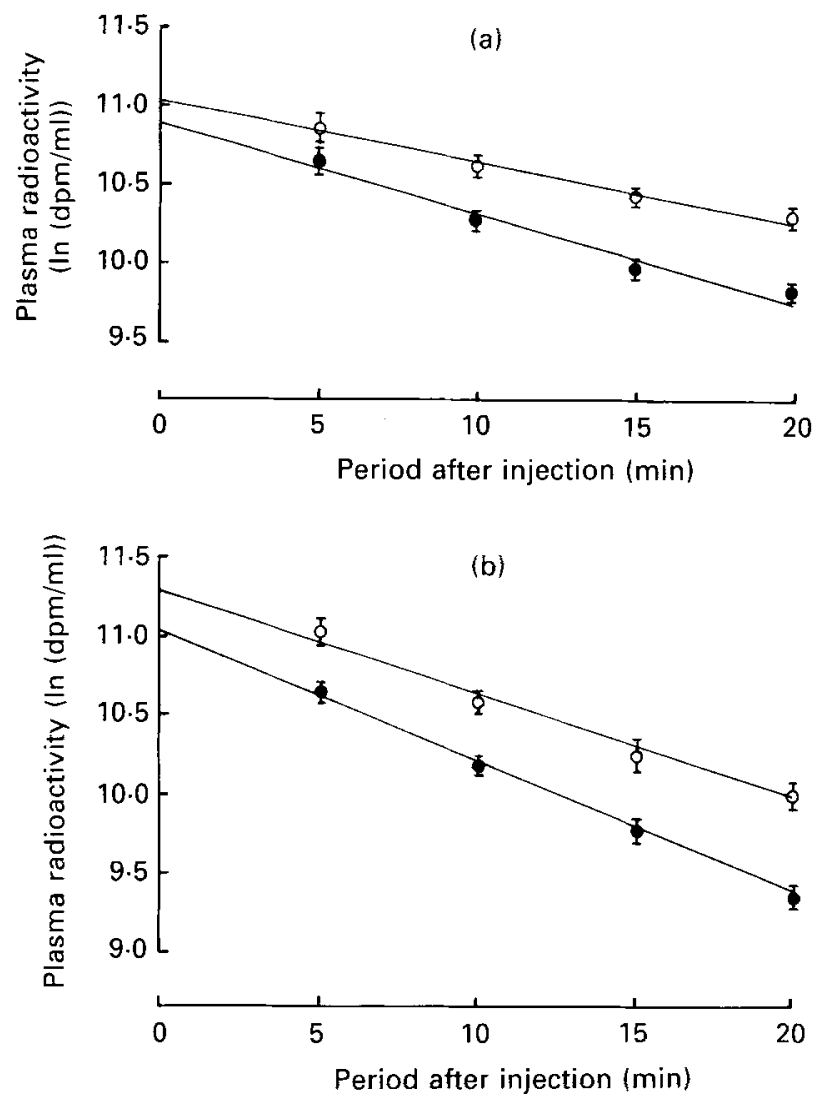

Fig. 1. The disappearance of plasma radioactivity following intravenous injection of $\left[1,2,6,7-{ }^{3} \mathrm{H}\right]$ corticosterone. Results are means with two standard errors, represented by vertical bars, for (a) males and (b) females. Groups of six rats were either fed ad lib. (O) or fasted for $48 \mathrm{~h}(\mathrm{O})$. Blood samples were taken at 5,10 and $15 \mathrm{~min}$ from a cannula implanted in the tail artery, and at $20 \mathrm{~min}$ by cardiac puncture. $\mathrm{dpm}$, disintegrations $/ \mathrm{min}$.

\section{RESULTS}

\section{Expt 1. Corticosterone clearance}

The decrease of plasma radioactivity with time followed an exponential pattern in all groups (Fig. 1). The gradient of this plot, taken to be the FCR, was higher in female rats than in males (Table 1). In both sexes, fasted rats had significantly lower FCR than did fed animals. Plasma corticosterone concentration was higher in females than in males, and was significantly increased by fasting in each sex $(+34$ and $+28 \%$ for males and females respectively). The volume of distribution of the $\left[{ }^{3} \mathrm{H}\right]$ corticosterone tended to be higher in females, but there was no significant difference between the fed and fasted groups of either sex.

In contrast with FCR and corticosterone concentration, the secretion rate of corticosterone did not differ between fed and fasted groups of either sex (Table 1). Secretion rates were substantially higher in females than in males. The metabolic clearance rate, however, was significantly decreased by fasting in both males and females, and the values did not differ between the sexes. 
FASTING AND PLASMA CORTICOSTERONE KINETICS
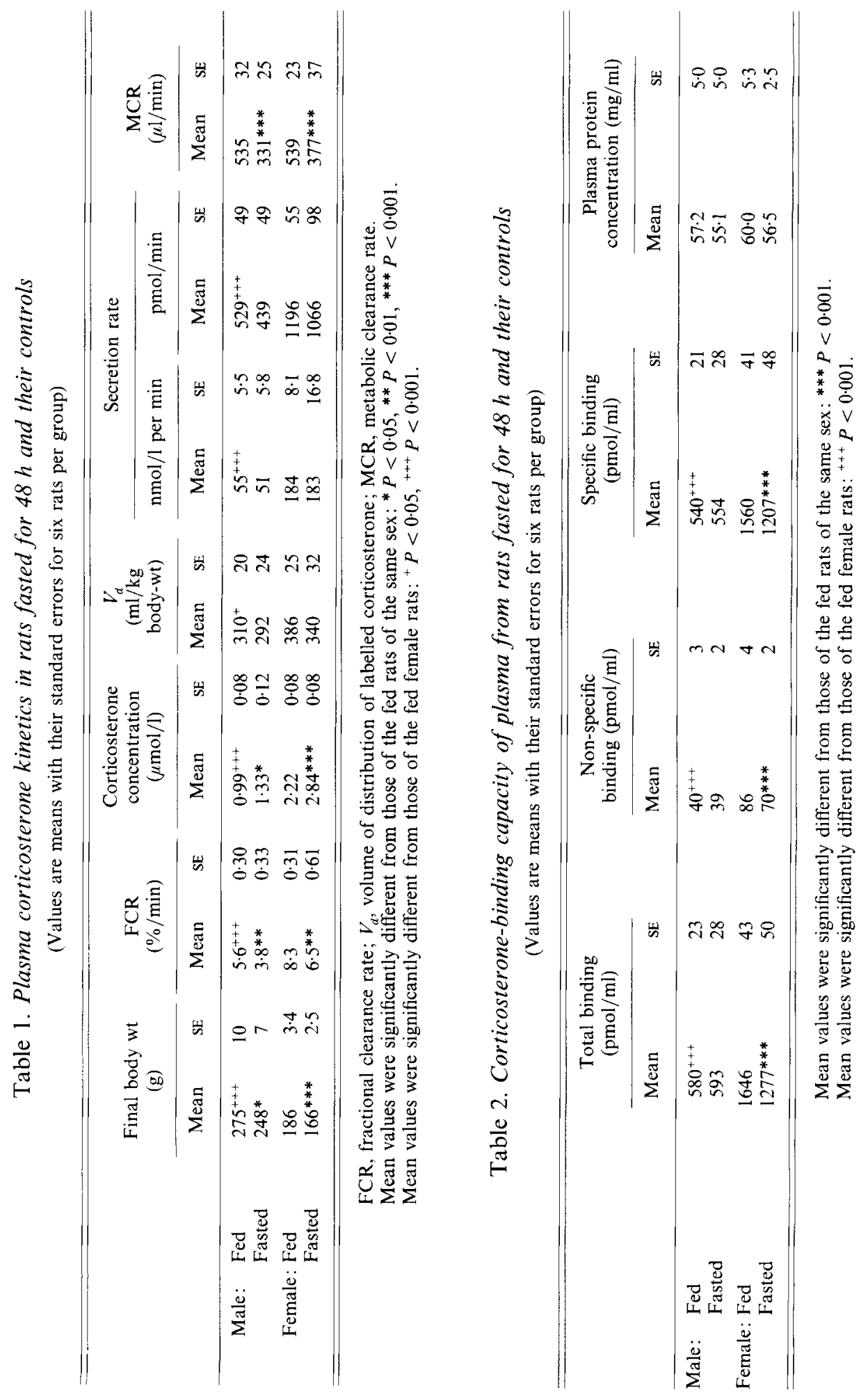


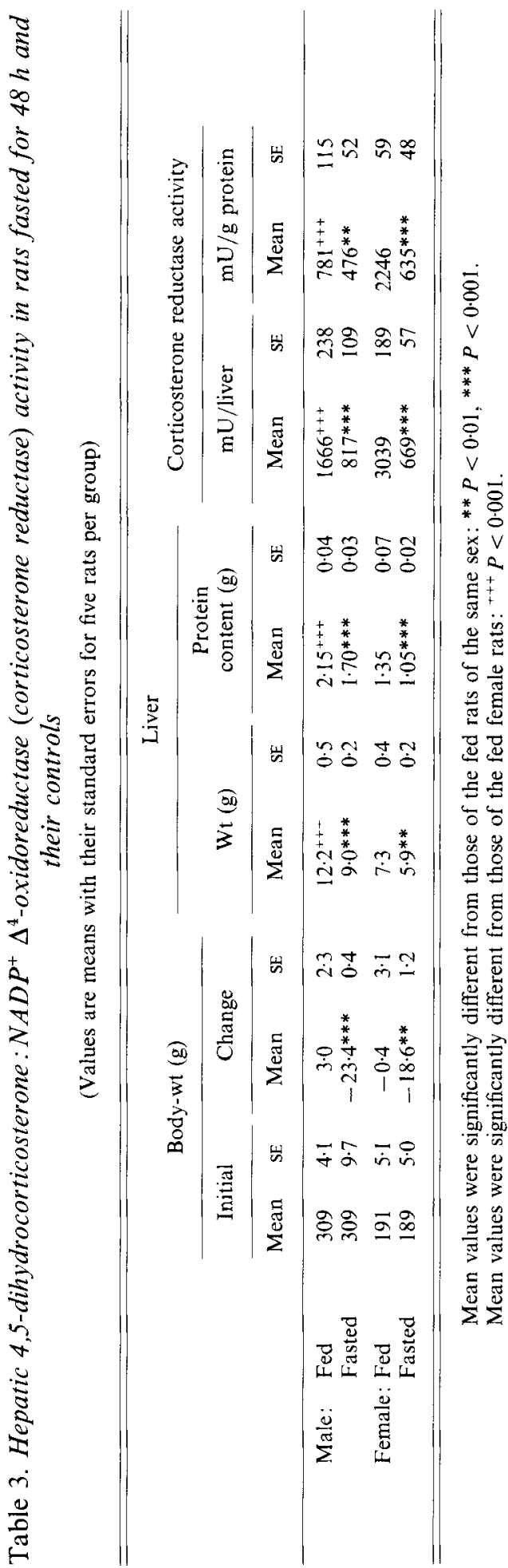



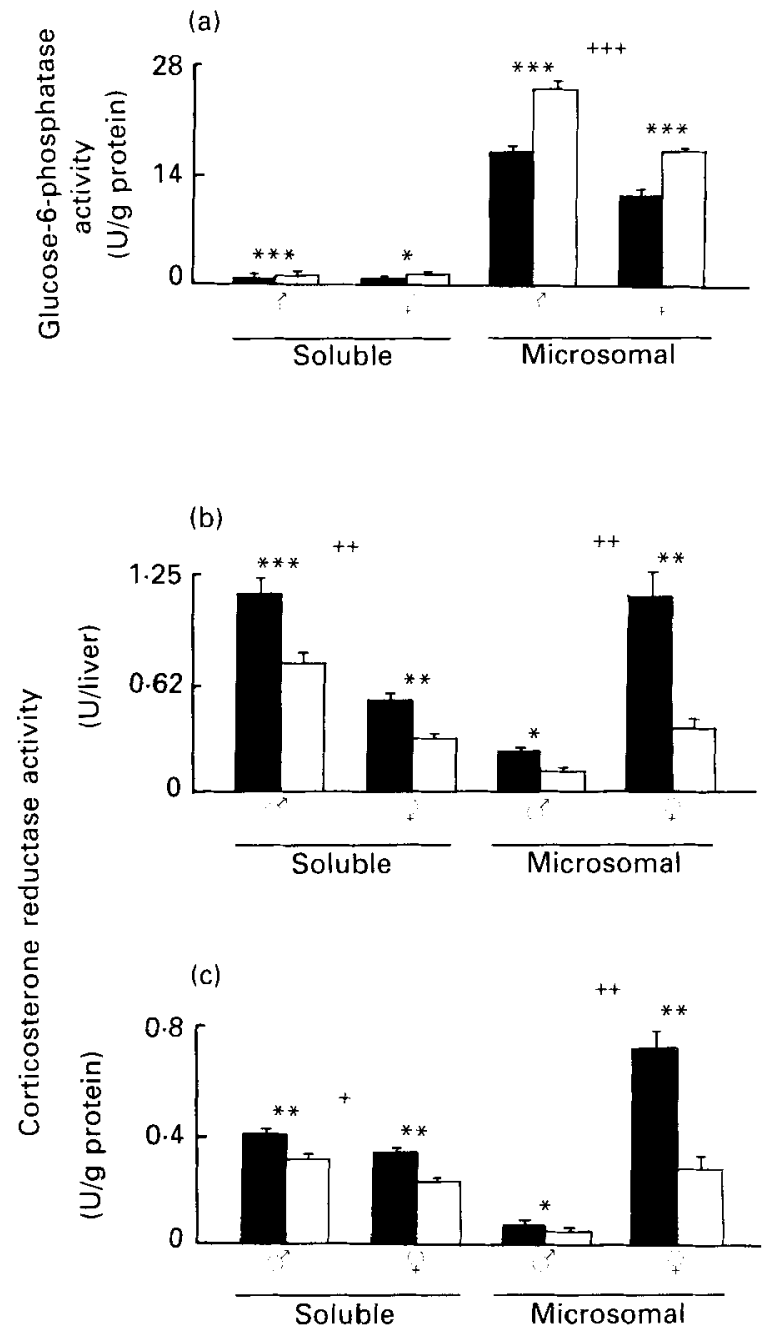

Fig. 2. Enzyme activities in soluble and microsomal fractions of liver homogenates from fed ( $\square$ ) and $48 \mathrm{~h}$-fasted ( $\square)$ rats. Values are means with their standard errors, represented by vertical bars, for four rats per group. (a), Glucose-6-phosphatase (EC 3.1.3.9); (b), (c), 4,5-dihydrocorticosterone: NADP ${ }^{+} \Delta^{4}$-oxidoreductase (corticosterone reductase) expressed as $U /$ liver and $U / g$ protein respectively. Mean values for fed group were significantly different from those of fasted group of the same sex: ${ }^{*} P<0.05,{ }^{* *} P<0.01,{ }^{* * *} P<0.001$. Mean values for fed males were significantly different from those of fed females: ${ }^{+} \boldsymbol{P}<0.05,{ }^{++} \boldsymbol{P}<0.01,^{+++} \boldsymbol{P}<0.001$.

\section{Expt 1. Binding capacity of plasma $C B G$}

Plasma from female rats bound substantially more corticosterone than did that from males (Table 2). In males, fasting had no effect on any of the measures of binding. In females, however, fasting reduced specific, high-affinity binding by $23 \%(P<0.001)$. There was also a small reduction in low-affinity, non-specific binding. In neither sex was total plasma protein concentration affected by fasting.

\section{Expt 2. Corticosterone reductase activity in whole liver homogenates}

Liver weight and protein content were significantly reduced after fasting in both sexes, by $20-30 \%$ (Table 3 ). Enzyme activity was expressed in two ways, namely per whole liver and 
per $g$ liver protein. The fed male rats showed substantially lower enzyme activity than the females, using both methods of expression. Fasting in male rats significantly reduced activity expressed per whole liver $(-51 \%)$ and per g protein $(-39 \%)$. In females the reductions were somewhat larger than those found in males $(\mathrm{U} /$ liver $-78 \%, \mathrm{U} / \mathrm{g}$ protein $-72 \%)$.

\section{Expt 3. Corticosterone reductase activity in soluble and microsomal fractions}

The changes in liver size were similar to those in Expt 2 (values not given). The results for the marker enzyme glucose 6-phosphatase are shown in Fig. 2(a). In all groups, more than $90 \%$ of the measured enzyme activity was located in the microsomal fraction. Fasting significantly increased microsomal glucose-6-phosphatase activity in both sexes.

Results for corticosterone reductase activity, expressed both per whole liver and per $\mathrm{g}$ liver protein, are shown in Fig. 2(b-c). In the soluble fraction, fed male rats had higher enzyme activities than did females. Fasting produced significant reductions of enzyme activity in this fraction for both sexes. Expressed in percentage terms, these changes were slightly greater in females than in males. Microsomal enzyme activity was substantially higher in fed female rats than in males. Fasting again produced significant reductions in activity, and these were considerably more pronounced in females than in males. Thus, for example, enzyme activity expressed as $\mathrm{mU} / \mathrm{g}$ protein was reduced by $61 \%$ in the fasted females, whereas in the males this value was only $34 \%$.

\section{DISCUSSION}

The main aim of the present study was to use kinetic measurements of hormone clearance to identify the cause of the increased plasma corticosterone levels found during fasting. Although Herbst et al. (1960) have previously reported a reduction of FCR in fasted rats, they were unable to estimate secretion rates due to the lack of an accurate corticosteroid assay at that time. The same authors found that fasting decreased corticosterone reductase activity in whole liver slices, but did not identify whether this change was due to the soluble or microsomal form of the enzyme. The large sex differences in corticosterone metabolism found here were expected from previous work (Glenister \& Yates, 1961; Kitay, 1961; Gala $\&$ Westphal, 1965). It is thought that they are, at least in part, the result of neonatal imprinting by testosterone (Jansson et al. 1989).

The disappearance of radioactivity up to $2 \mathrm{~h}$ after a bolus injection of glucocorticoid is known to follow complex kinetics (Tait \& Burstein, 1964; Carsia et al. 1988; Leeper et al. 1988; White et al. 1989). In the present study a shorter time period of $20 \mathrm{~min}$ was used, and over this interval the disappearance of radioactivity could be adequately described using first-order kinetics. The errors introduced by assuming simple exponential kinetics are not thought to be great for corticosteroid hormones (Tait, 1963).

After a $48 \mathrm{~h}$ fast, both sexes of rat showed reductions in FCR and metabolic clearance rate, increases in plasma corticosterone concentration and no change in secretion rate. These changes are consistent with the hypothesis that increased plasma steroid levels are due to a reduction in the rate of removal of hormone from the plasma, with no change in the rate of secretion from the adrenal gland. The reduction of $22 \%$ in the FCR of fasted females compares with a $24 \%$ decrease found by Herbst et al. (1960) after an overnight fast.

The results should be interpreted with caution, however, since the plasma corticosterone levels obtained in the fed rats were somewhat higher than those found when steps were taken to minimize disturbance of the animals (see p. 118). It is, thus, possible that the adrenal cortex was stimulated to some extent in both groups by handling, anaesthesia or surgery; this might in turn have obscured differences in corticosterone secretion caused by fasting per se. Indeed, the increased levels of adrenocorticotrophin found during 
malnutrition (Carsia et al. 1988; Beer et al. 1989) would argue that the adrenal secretion of glucocorticoids is raised to some extent. The increase in corticosterone concentration caused by the procedure was, however, only 74 and $42 \%$ for males and females respectively, which is much less than the 4-5-fold change recorded after a standard restraint stress (Stewart et al. 1988). It seems unlikely that this relatively small artefact of handling could completely obscure any major stimulation of hormone secretion due to fasting. Previous work suggests that handling stress reduces but does not abolish the effect of malnutrition on plasma corticosterone concentration (Chowers et al. 1969; Stewart et al. 1988). The importance of reduced clearance is also emphasized by the large reduction in activity of hepatic corticosterone reductase in fasted rats. Reduced clearance would, moreover, be likely to amplify the effects of any small concurrent increase in hormone secretion which did occur.

To overcome the problem of hypercorticosteronaemia caused by handling would require a more complex experimental protocol than that used here. White et al. (1989) waited for $1 \mathrm{~h}$ after induction of pentobarbital anaesthesia, in an attempt to restore basal hormone levels before measuring clearance. They did not verify, however, whether adrenal function was suppressed by prolonged anaesthesia. An alternative approach might involve the use of conscious, chronically-implanted rats.

A further possible source of inaccuracy arises from the use of total plasma radioactivity to calculate clearance rates. The preliminary study (p. 119) suggested that up to $25 \%$ of the radioactivity was present in corticosterone metabolites $20 \mathrm{~min}$ after injection. Assuming that the proportion of corticosterone metabolites increased progressively during the period of the turnover measurement, the clearance rates obtained will be underestimates. Two considerations, however, suggest that this factor is unlikely to have greatly influenced the difference between fed and fasted groups. Firstly, the radioactivity in the plasma of the fasted male and female rats at 20 mins after injection was respectively 61 and $88 \%$ higher than that found in the fed rats. This greatly exceeds the amount which might be attributed to metabolite accumulation. Secondly, in the presence of reduced corticosterone catabolism, the accumulation of radioactive metabolites would most likely be diminished, since the rate-limiting reaction for corticosterone catabolism is the initial step in the reductive pathway, catalysed by corticosterone reductase (Tomkins, 1956). The inaccuracy introduced by using total radioactivity would thus result in an underestimate of the difference between fed and fasted groups.

The volume of distribution of the radioactive corticosterone amounted to $30-40 \%$ of body weight, which is very similar to that found by previous workers (Carsia et al. 1988; Leeper et al. 1988; White et al. 1989). This value is substantially more than the blood volume, and it is possible that the injected corticosterone equilibrates with the total extracellular fluid volume (White et al. 1989). A further possibility is that, despite the assumption of complete and immediate mixing, newly-injected steroid may be preferentially catabolized, perhaps because it is not bound to plasma proteins.

The kinetic results showing reduced FCR are supported by the activity of corticosterone reductase measured in liver homogenates from fasted rats. The levels of activity were higher than in a previous study (Woodward et al. 1990); this is attributable to the analyses being carried out on fresh rather than frozen tissue. This enzyme exists in two forms: one in the microsomal fraction catalyses formation of the $5 \alpha$ product, while another in the cytosol produces the $5 \beta$ stereoisomer (Tomkins, 1956). In Expt 3 these forms were separated using differential centrifugation. The distribution of glucose-6-phosphatase confirmed effective separation of the two fractions; the increased levels of the latter enzyme in fasted rats are consistent with its role in gluconeogenesis (Weber \& Cantero, 1954). As found previously (Dorfman \& Ungar, 1965), the high level of corticosterone reductase in female rats is 
attributable to increased levels of the microsomal enzyme. Fasting reduced corticosterone reductase activities in both the soluble and microsomal fractions. It is clear from the present experiment that the large decrease in enzyme activity in whole homogenates from female rats can be attributed to changes in the microsomal enzyme. It is possible that this form of the enzyme is more sensitive to fasting than is that in the cytosol.

It is unclear why fasting should reduce CBG levels in females but not in males, but one possibility is that a $48 \mathrm{~h}$ fast is a greater stress for the females, which have a smaller body size. The function of CBG is not understood, but corticosterone may be less readily available to some tissues when bound to this protein (Ballard, 1979). A reduction in the CBG capacity would then be expected to amplify the effects of increased total hormone concentrations in plasma. It has also been suggested that there is an inverse relationship between CBG levels and the FCR of corticosterone (Ballard, 1979; Leeper et al. 1988). Such a mechanism does not seem to occur in the fasted rat, however, since reduced clearance rates were not associated with increased levels of binding protein.

The present study provides evidence that fasting hypercorticosteronemia is caused predominantly by a reduction in hormone clearance from the plasma, and that this is related to a reduced capacity for hepatic metabolism of the hormone. It seems reasonable that the liver should regulate the response of corticosteroids to nutritional stress, since this organ is uniquely placed to monitor the flow of substrates for gluconeogenesis. Recent evidence suggests that hepatic secretion of somatomedins and somatomedin inhibitors also changes in response to nutritional status (Goldstein \& Phillips, 1989). Thus the liver has considerable significance in regulating the endocrine response to undernutrition.

This study was carried out under the terms of a contract with the Ministry of Agriculture, Fisheries and Food.

\section{REFERENCES}

Baginski, E. S., Foa, P. P. \& Zak, B. (1974). Glucose-6-phosphatase. In Methods of Enzymatic Analysis, 2nd English ed., pp. $876-880$ [H. U. Bergmeyer, editor]. Basel: Verlag Chemie.

Ballard, P. L. (1979). Delivery and transport of glucocorticoids to target cells. In Glucocorticoid Hormone Action, pp. 25-48 [J. D. Baxter and G. G. Rousseau, editors]. Berlin: Springer-Verlag.

Beer, S. F., Bircham, P. M. M., Bloom, S. R., Clark, P. M., Hales, C. N., Hughes, C. M., Jones, C. T., Marsh, D. R., Raggatt, P. R. \& Findlay, A. L. R. (1989). The effect of a 72-h fast on plasma levels of pituitary, adrenal, thyroid, pancreatic and gastrointestinal hormones in healthy men and women. Journal of Endocrinology 120 , $337-350$.

Carsia, R. V., Weber, H. \& Lauterio, T. J. (1988). Protein malnutrition in the domestic fowl induces alterations in adrenocortical function. Endocrinology 122, 673-680.

Chamness, G. C. \& McGuire, W. L. (1975). Scatchard plots: common errors in correction and interpretation. Steroids 26, 538-542.

Chowers, I., Einst, R. \& Feldman, S. (1969). Effects of starvation on levels of corticotrophin releasing factor, corticotrophin and plasma corticosterone in rats. Acta Endocrinologica 61, 687-694.

Dawson, R. M. C., Elliott, D. C., Elliott, W. H. \& Jones, K. M. (1969). Data for Biochemical Research, 2nd ed., p. 619. London: Oxford University Press.

Dorfman, R. I. \& Ungar, F. (1965). Metabolism of Steroid Hormones, 1st ed., pp. 406-409. New York: Academic Press.

Gala, R. R. \& Westphal, U. (1965). Corticosteroid-binding globulin in the rat: studies on the sex difference. Endocrinology 77, 841-851.

Glenister, D. W. \& Yates, F. E. (1961). Sex differences in the rate of disappearance of corticosterone-4-C $\mathrm{C}^{14}$ from plasma of intact rats. Endocrinology 68, 747-758.

Goldstein, S. \& Phillips, L. S. (1989). Nutrition and somatomedin : nutritionally regulated release of somatomedins and somatomedin inhibitors from perfused livers in rats. Metabolism 38, 745-752.

Herbst, A. L., Yates, F. E., Glenister, D. W. \& Urquhart, J. (1960). Variations in hepatic inactivation of corticosterone with changes in food intake: an explanation of impaired corticosteroid metabolism following noxious stimuli. Endocrinology 67, 222-238.

Jansson, J.-O., Oscarsson, J., Mode, A. \& Ritzen, E. M. (1989). Plasma growth hormone pattern and androgens influence the levels of corticosteroid-binding globulin in rat serum. Journal of Endocrinology 122, 725 -732. 
Kitay, J. I. (1961). Sex differences in adrenal cortical secretion in the rat. Endocrinology 68, 818-824.

Leeper, L. L., Schroeder, R. \& Henning, S. J. (1988). Kinetics of circulating corticosterone in infant rats. Pediatric Research 24, 595-599.

Lindberg, M., Shire, J. G. M., Doering, C. H., Kessler, S. \& Clayton, R. B. (1972). Reductive metabolism of corticosterone in mice: differences in NADPH requirements of liver homogenates of males of two inbred strains. Endocrinology 90, 81-92.

Martin, C. E., Cake, M. H., Hartmann, P. E. \& Cook, I. F. (1977). Relationship between foetal corticosteroids, maternal progesterone and parturition in the rat. Acta Endocrinologica 84, 167-176.

Munck, A., Guyre, P. M. \& Holbrook, N. J. (1984). Physiological functions of glucocorticoids in stress and their relation to pharmacological actions. Endocrine Reviews 5, 25-44.

Norman, A. W. \& Litwack, G. (1987). Hormones. New York: Academic Press

Snedecor, G. W. \& Cochran, W. G. (1978). Statistical Methods, 6th ed., p. 324. Ames, Iowa: Iowa State University Press.

Stewart, J., Meaney, M. J., Aitken, D., Jensen, L. \& Kalant, N. (1988). The effects of acute and life-long food restriction on basal and stress-induced serum corticosterone levels in young and aged rats. Endocrinology 123 , 1934-1941.

Tait, J. F. (1963). The use of isotopic steroids for the measurement of production rates in vivo. Journal of Clinical Endocrinology and Metabolism 23, 1285-1297.

Tait, J. F. \& Burstein, S. (1964). In vivo studies of steroid dynamics in man. In The Hormones, vol. 5, pp. 441-557 [G. Pincus, K. V. Thimann and E. B. Astwood, editors]. New York: Academic Press.

Tischler, M. E., Henriksen, E. J. \& Cook, P. H. (1988). Role of glucocorticoids in increased muscle glutamine production in starvation. Muscle and Nerve 11, 752-756.

Tomkins, G. M. (1956). Enzymatic mechanisms of hormone metabolism. 1. Oxidation-reduction of the steroid nucleus. Recent Progress in Hormone Research 12, 125-133.

Ulrich, F. \& Long, C. N. H. (1956). Effects of stress on serum $\mathrm{C}^{14}$ levels in rats following administration of hydrocortisone-4-C $\mathrm{C}^{14}$ and corticosterone-4-C $\mathrm{C}^{14}$. Endocrinology 59, 170-180.

Waterlow, J. C., Garlick, P. J. \& Millward, D. J. (1978). Protein Turnover in Mammalian Tissues and in the Whole Body. Amsterdam: Elsevier/North Holland Biomedical Press.

Waynforth, H. B. (1980). Experimental and Surgical Technique in the Rat. London: Academic Press.

Weber, G. \& Cantero, A. (1954). Glucose-6-phosphatase studies in fasting. Science 120, 851-852.

White, B. D., Corll, C. B. \& Porter, J. R. (1989). The metabolic clearance rate of corticosterone in lean and obese male Zucker rats. Metabolism 38, 530-536.

Woodward, C. J. H., Hervey, G. R., Oakey, R. E. \& Whitaker, E. M. (1990). The effect of fasting on plasma corticosterone kinetics in the anaesthetised rat. Proceedings of the Nutrition Society 49, 79A.

Yates, F. E., Herbst, A. L. \& Urquhart, J. (1958). Sex difference in rate of ring A reduction of $\Delta^{4}-3$-keto-steroids in vitro by rat liver. Endocrinology 63, 887-902. 